\title{
A multidisciplinary clinic for amyotrophic lateral sclerosis patients in Northeast Mexico
}

\author{
Hector R. Martínez*, Jose A. Figueroa-Sánchez, Leonel Cantú-Martínez, Ricardo Caraza, \\ Manuel de la Maza, Juan M. Escamilla-Garza, and Javier Valero-Gómez \\ Tecnológico de Monterrey, School of Medicine and Health Sciences, Monterrey, Nuevo León, Mexico
}

\begin{abstract}
Amyotrophic lateral sclerosis (ALS) is a late-onset neurodegenerative disorder characterized by rapid deterioration and selective death of motor neurons (MNS) in central nervous system. There is no effective therapy for ALS patients. Riluzole, only slightly delays disease progression. Edaravone was FDA approved as an intravenous therapy, however, this drug is expensive and has been applied in few cases in our country. There is compelling evidence patients who attend an ALS multidisciplinary clinic experience improved survival. An ALS multidisciplinary clinic was launched in our institution and adapted to our healthcare system. It is described the processes involved in the evaluation of patients in an all day long session where ALS patients are evaluated by several professionals from different specialties specially trained in the needs of subjects living with this disorder. We consider that this model of healthcare for patients with ALS may be useful in another healthcare institutions in our country.
\end{abstract}

Key words: Amyotrophic lateral sclerosis. Multidisciplinary clinic. Mortality. Survival.

\section{Clínica multidisciplinaria para pacientes con esclerosis lateral amiotrófica en el Noreste de México}

\section{Resumen}

Esclerosis Lateral Amiotrófica (ELA) es una enfermedad neurodegenerativa caracterizada por rápido deterioro y muerte selectiva de neuronas motoras en el sistema nervioso central. No existe tratamiento efectivo para los pacientes con ELA. El Riluzole solo prolonga discretamente la sobrevida. El Edaravone aprobado por la FDA como tratamiento intravenoso, es costoso y solo ha sido utilizado en algunos pacientes en nuestro país. Existe evidencia en los últimos años que el manejo multidisciplinario de los pacientes con ELA mejora la sobrevida. En nuestra institución efectuamos la apertura de la clínica multidisciplinaria para ELA. Describimos los procesos involucrados en la evaluación de los pacientes en una sesión durante todo un día, donde los pacientes son evaluados por médicos de diferentes especialidades y con entrenamiento en la evaluación de pacientes con ELA Consideramos que este modelo de atención para el cuidado de los pacientes que sufren este trastorno neurológico es útil y podría ser aplicado en otras instituciones del sector salud de nuestro país.

Palabras claves: Esclerosis lateral amiotrófica. Clínica multidisciplinaria. Mortalidad. Sobrevida.

Correspondence:

*Hector R. Martínez

E-mail: hector.ramon@tec.mx
Date of reception: 24-10-2019

Date of acceptance: 27-12-2019

DOI: 10.24875/RMN.19000144
Available online: $02-03-2020$ Rev Mex Neuroci. 2020;21(2):66-70

www.revmexneurociencia.com 1665-5044/@ 2019 Academia Mexicana de Neurología A.C. Published by Permanyer. This is an open access article under the CC BY-NC-ND license (http://creativecommons.org/licenses/by-nc-nd/4.0/). 


\section{Introduction}

Amyotrophic lateral sclerosis (ALS) is a late-onset neurodegenerative disorder characterized by rapid deterioration and selective death of motor neurons (MNs) in cerebral cortex, brain stem, and spinal cord. ${ }^{1,2}$ Clinical features are attributable to the superimposition of motor deficit occurring by damage in upper motor neurons (UMN) and lower motor neurons (LMN). Motor phenotypes are highly heterogeneous and defined by, 1) the body region of onset; 2) the relative mix of UMN and LMN involvement; and 3) the rate of progression. ${ }^{3}$ According to different series, mean survival of ALS patients ranges from 15.7 months to 47 months after presentation. ${ }^{4-7}$

At present, there is no effective therapy for ALS patients. ${ }^{6-10}$ Riluzole, until recently was the only medication approved by the FDA. However, this drug only slightly delays disease progression. 3,6,7 Two years ago Edaravone was FDA approved as an intravenous therapy for ALS patients. ${ }^{11}$ However, this drug is expensive and so far, has been applied in very few cases in our country. Non-invasive ventilation (NIV) confers a survival and quality of life benefits in patients with ALS. It remains unclear whether gastrostomy improves survival, as there have been no randomized controlled trials. ${ }^{9}$

Multidisciplinary clinic has been settled in a number of countries (Ireland, Holland, Italy, England, USA). There is compelling evidence that those who attend in a multidisciplinary clinic experience improved survival..$^{9-14}$ The processes by which survival advantage is conferred remain unclear. Services through a network clinic, did not demonstrate a survival benefit for ALS patients attending or being referred to a centralized clinic. ${ }^{9}$ In our country, the common clinical approach to patients with ALS provided by the social security system is through network clinic and referred to a second or third level hospital to be evaluated and managed by neurologist without multidisciplinary health care team of professionals trained in the needs of ALS subjects. ${ }^{6,7}$ In the private healthcare system, usually patients suffering of motor neuron symptoms are initially evaluated by a general practitioner, orthopedist and traumatologist and finally those patients are sent to a neurologist that usually request other healthcare specialists (neurophysiologist, respiratory therapist, physical therapist and neuroradiologist) to establish the diagnosis of definite ALS and suggest and initial management. However, an appropriate follow-up by a multidisciplinary health care team is usually missing. In Mexican population, it has been reported that the mean interval between clinical onset to clinical diagnosis is 13.9 months (ranges from 1 to 42 months) including ALS patients evaluated in social security system and in private practice healthcare system. ${ }^{6}$

\section{Primary ALS clinic}

The school of medicine and the Hospital San Jose of the Tecnológico de Monterrey started in 2005 an ALS care clinic for the evaluation and management of patients with ALS. At that time, in this care clinic participated a neurologist with specialist expertise in ALS, a psychologist, two residents of the neurology residence program, two neuroscience researchers and one pulmonary physician. Since information about demographic characteristics of Mexican ALS patients was lacking, after this clinic commencement, we settled a population-based epidemiological study to define the clinical and demographic characteristics of Mexican ALS patients. ${ }^{6}$ Referred and interested patients with motor neuron disease were evaluated between June 2005 and May 2010. Patients who were born and were residing in Mexico were included in a retrospective and longitudinal study. From 141 patients that were evaluated in that period, 85 were Mexicans and only 65 of them fulfilled the El Escorial clinical and neurophysiological criteria for definite ALS. Two cases (3.3\%) were classified as having familial ALS (fALS). Most of the Mexican patients $(65 \%)$ came from regions with the highest socioeconomic status. ${ }^{6}$ The explanation for this finding was related to the location of this ALS clinic into a private hospital. After this information was obtained, we started to progress this clinic to the concept of multidisciplinary care model for ALS subjects and adjust our benchmark approach to patients with ALS.

\section{Healthcare system in Mexico}

There are three healthcare systems in Mexico: 1) the social security system subsidized by workers, entrepreneurs and government funding; 2) the ministry of health system includes hospitals and academic institutions including national institutes of health that are supported by federal and state government contributions; and 3) the private healthcare system including hospitals and outpatient's clinics held by private insurance companies, private insurance service providers and payment capacity by individuals. Services through a network clinic in these systems usually referred patients with possible ALS or motor neuron disease to a third level of attention hospitals for evaluation by neurologist, so far, our country did not have multidisciplinary clinic for ALS patients. 


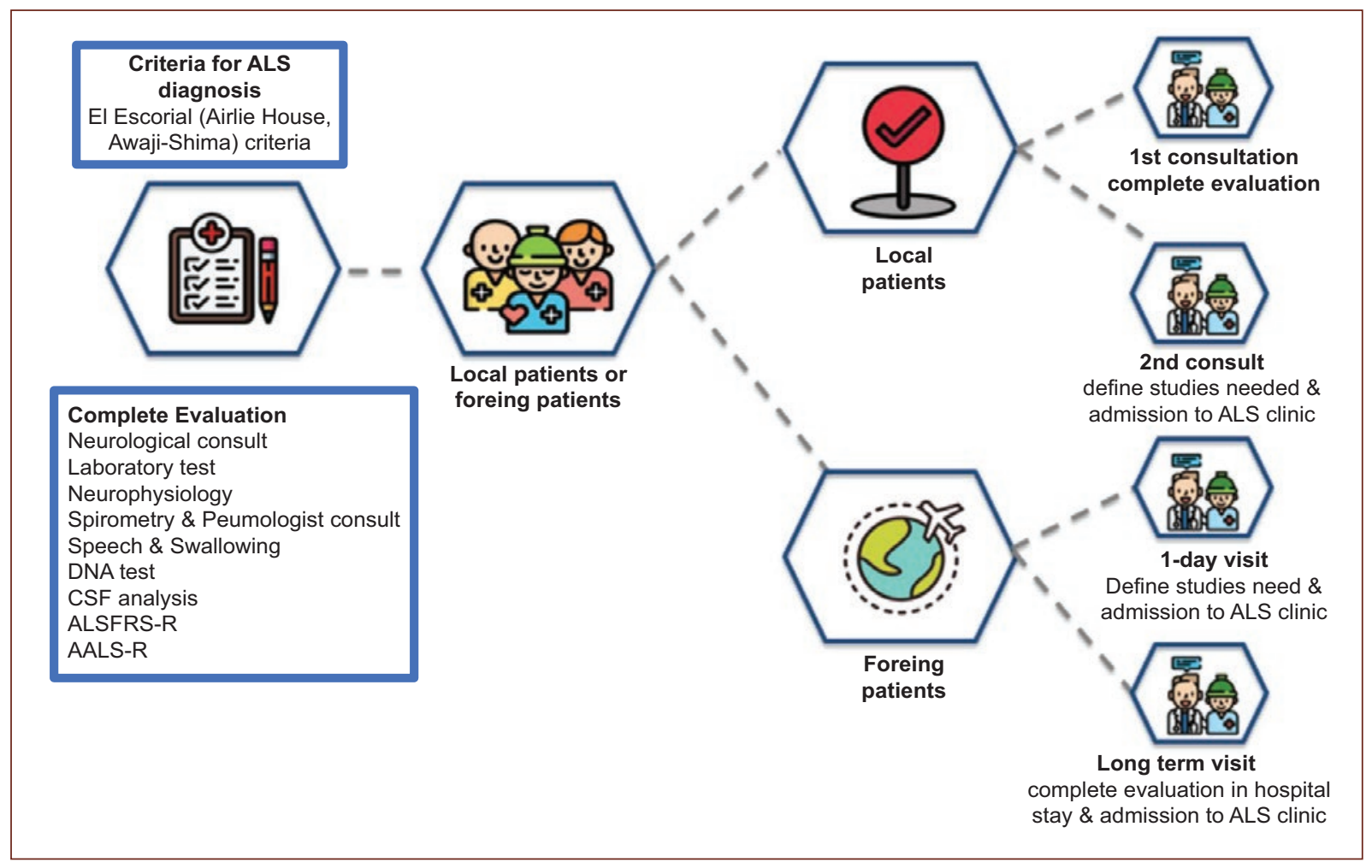

Figure 1. A schematic representation of ALS multidisciplinary clinic at Neurology and Neurosurgery Institute, TecSalud at the Tecnológico de Monterrey. ALSFRS-R: ALS Functional Rating Scale Revised, AALS-RS: Appel ALS Rating Scale.

\section{Multidisciplinary ALS clinic}

The multidisciplinary health care model for ALS incorporates professionals specially trained in the needs of subjects living with this disorder, allowing them to receive care from each discipline during a single visit. The care team involves a neurologist, physical therapist, occupational therapist, respiratory therapist, nurse, dietitian, speech language pathologist, social worker and mental health professional. There are a number of multidisciplinary ALS clinics in USA that are ALS Association Certified Treatment Centers of Excellence. ${ }^{14}$ In European Union there are also a number of countries having multidisciplinary clinics for ALS patients including Ireland, Holland, Italy, England, Switzerland, Portugal, Belgium and other European countries. $^{8-10,12}$ In USA since 1998, the ALS association's national network of Certified Treatment Centers of Excellence has provided the evidence-based system for the multidisciplinary ALS care centers. Each ALS clinic must meet the ALS Association's clinical care and treatment standards, which are based on the American Academy of Neurology practice parameters, more than one hundred ALS clinics are certified in USA. ${ }^{14}$
After Dr. Stanley Appel invite us for attending his ALS multidisciplinary clinic in the neurology service at the Methodist hospital in Houston Texas USA, we witnessed the processes involved in the evaluation of ALS patients in the first ALS multidisciplinary clinic started in USA during the last century. After this visit, we acquired from Dr Appel the methodology to establish an ALS multidisciplinary clinic in our institution according to our private healthcare system. We consider to establish a model of health care that may be also useful in the social security system and ministry of health system in Mexico. Dr. Appel ALS multidisciplinary clinic has a team of 21 professionals from 11 specialties that are attending ALS patients in an all day long session at least 6 hours duration once a month. ALS patients are evaluated by several professionals from different specialties.

\section{TecSalud ALS multidisciplinary clinic}

During the last year we started working in adapt our healthcare system to an ALS multidisciplinary clinic as a care model for ALS patients useful to our institution as well as to other institutions and hospitals in our country. Since patients suffering of motor neuron symptoms or 


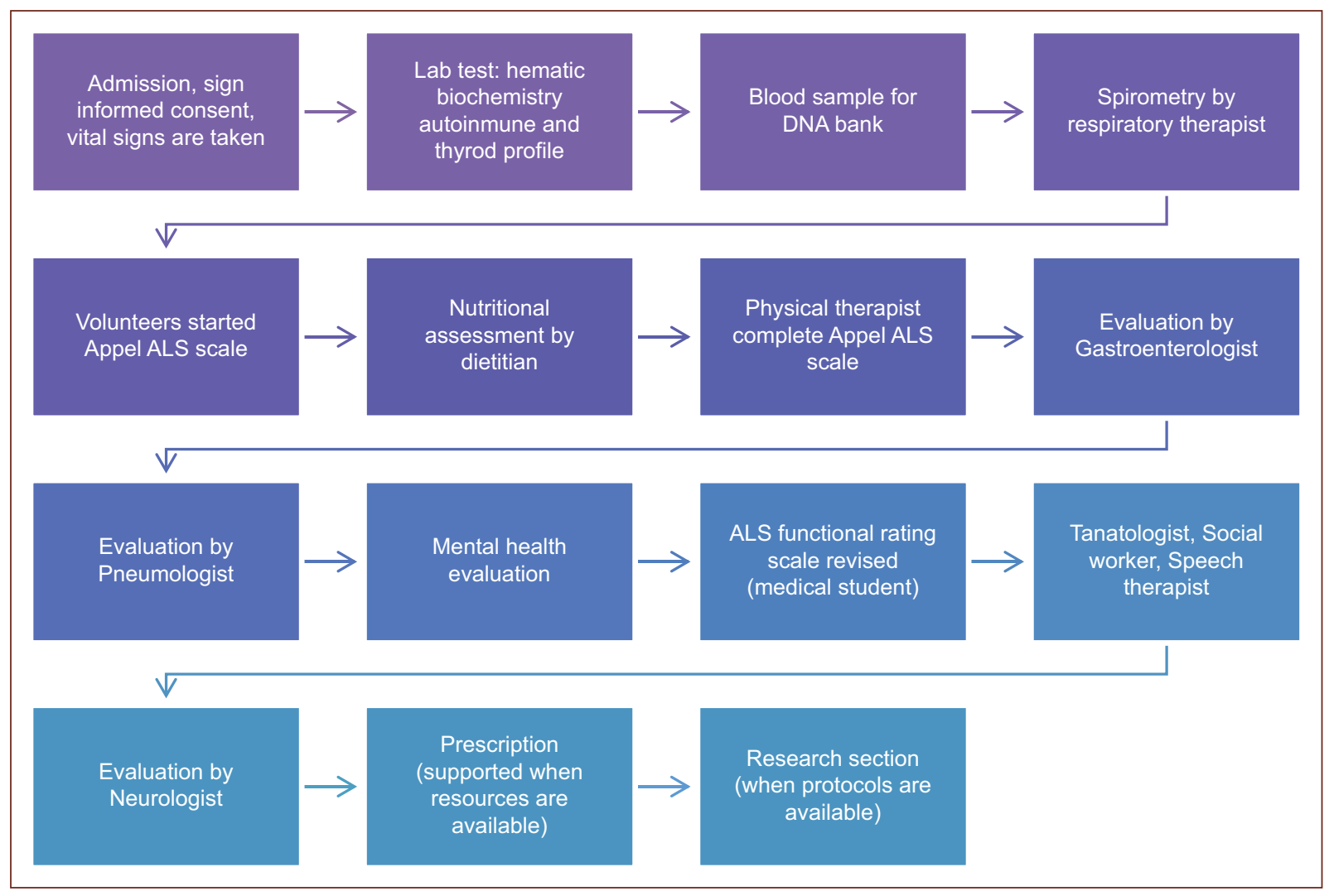

Figure 2. Patient flow diagram attending the TecSalud ALS Multidisciplinary Clinic.

definite ALS are sent to our institution from our location, other states of Mexico and abroad, we decided to present different options for evaluation patient from our location (local) outside or abroad (foreign) (figure 1). However, a complete evaluation is required to establish the diagnosis of definite ALS according to El Escorial (Arlie House and Awaji-Shima) clinical and neurophysiological criteria. Patients with ALS are sent to TecSalud ALS Multidisciplinary Clinic that are evaluated in half a day session every three months. The patients are assessed by a team of 14 professionals (Physical Therapist, Speech Therapist, Dietitian, Psychologist, Mental Health, Gastroenterologist, Pneumologist and Neurologists) from 8 specialties. Six volunteers participate accomplishing upper extremities muscle strength items from the Appel ALS scale. ${ }^{15}$ Fifteen medical students collect demographic information, collect samples to the DNA blood bank, help physicians from different specialties in the evaluation of patients and in fulfilling the ALS functional rating scale revised. The participation of senior students of the school of medicine at the Tecnológico de Monterrey under supervision from professionals specially trained in the needs of subjects living with disorder, help them to learn about diagnostic approach and follow up of ALS patients. The patients follow a pre-established order (figure 2).

During the present year (2019) the ALS multidisciplinary clinic performed four sessions. Thirteen patients were evaluated in the first session, $18 \mathrm{ALS}$ patients in the second and third sessions and 20 patients in the last one. A total of 69 evaluations have been performed in 28 patients with definite ALS patients attended these four sessions at the TecSalud ALS multidisciplinary clinic. There were 11 females (age ranges 40 to 72 years, mean of 55.6 years old) and 17 males (age ranges 39 to 68 years mean of 58.7 years old). The patients came from different states of our country including Nuevo Leon, Coahuila, Tamaulipas, Jalisco, Zacatecas, Guanajuato and Baja California. The total costs of each session was supported by TecSalud and the physicians participating in the ALS multidisciplinary clinic, did not receive remuneration.

\section{Conclusion}

In conclusion, since there is no effective therapy for ALS patient ${ }^{6}$ and the compelling evidence indicates that those patients who attend an ALS multidisciplinary clinic 
experience improved survival-10,12-14; an ALS multidisciplinary clinic has been settled in our institution. To our knowledge, this is the first ALS multidisciplinary clinic in Mexico. The processes by which survival advantage is conferred by this multidisciplinary approach remain unclear. ${ }^{8}$ We consider that the survival improvement may be due to an early and appropriate nutritional and respiratory support established by professionals specially trained in different disciplines applied to the needs of ALS subjects. Our ALS multidisciplinary clinic adapted to our own healthcare system may be useful in another healthcare institutions in our country, adequate to improve life expectancy and quality of life in patients suffering of ALS.

\section{Acknowledgments}

We would like to thank the Director of the ALS Association, Dr. Pablo Ferrara, as well as the Director of Tecsalud Dr. Javier Valero Gomez, and all the physicians, nurses and volunteers for their invaluable support.

\section{Financial support and sponsorship}

None.

\section{Conflicts of interest}

There are no conflicts of interest.

\section{Ethical disclosures}

Protection of human and animal subjects. The authors declare that no experiments were performed on humans or animals for this study.
Confidentiality of data. The authors declare that no patient data appear in this article.

Right to privacy and informed consent. The authors declare that no patient data appear in this article.

\section{References}

1. Mills KR. The natural history of central motor abnormalities in amyotrophic lateral sclerosis. Brain 2003; 126: 2558-2566

2. Ringel SP, Murphy JR, Alderson MK, et al. The natural history of amyotrophic lateral sclerosis. Neurology. 1993; 43: 1316-1322

3. Ravits JM, La Spada AR. ALS motor phenotypes heterogeneity, focality and spread. Deconstructing motor neuron degeneration. Neurology. 2009; 73: $805-811$

4. Zoccolella S, Belghi E, Palagano G. Analysis of survival and prognostic factors in amyotrophic lateral sclerosis: a population based study. J Neurol Neurosurg Psychiatry. 2008; 79:33-37

5. Horton DK, Mehta P, Antao VC. Quantifying a Nonnotifiable Disease in the United States. The National Amyotrophic Lateral Sclerosis Registry Model. JAMA 2014; 312 (11) 1097-1098

6. Martinez HR, Molina-Lopez JF, Cantu-Martinez L, et al. Survival and clinical features in Hispanic amyotrophic lateral sclerosis patients. Amyotroph Lateral Scler. 2011; 12: 199-205

7. Martínez HR, Parada-Garza JD, Meza ME et al. Esclerosis lateral amiotrófica. Contribución de la neurología mexicana de 1998 a 2014. Rev. Mex Neuroci, 2014; 15(6): 355-362

8. Traynor BJ, Alexander M, Corr B et al. Effect of a multidisciplinary amyotrophic lateral sclerosis (ALS) clinic on ALS survival: a population based study, 1996-2000. J Neurol Neurosurg Psychiatry 2003; 74:1258-1261.

9. Rooney J, Byrne S, Heverin M, et al. Survival analysis of Irish amyotrophic lateral sclerosis patients diagnosed from 1995-2010. van der Brug MP, editor. PLoS One 2013; 8: e 74733.

10. Van den Berg JP, Kalmijn S, Lindeman E. Multidisciplinary ALS care improves quality of life in patients with ALS. Neurology 2005; 65:1264-7.

11. Hardiman O, van der Berg LH. Edaravone: a new treatment for ALSon the horizon? Lancet Neurol 2017; 16: 490-491

12. Zoccolella S, Beghi E, Palagano G. ALS multidisciplinary clinic and survival. Results from a population-based study in Southern Italy. J Neurol 2007; 254: 1107-1112.

13. Appel S. First multidisciplinary care clinical for patients with ALS in United States. Neurological Institute, Methodist Hospital at Houston Texas, USA. www.houstonmethodist.org/neurology/locations/texas-medical-center/clinical-programs/als-clinic/.

14. ALS Association Communications Department. mediarelations@alsa-national.org

15. Appel V, Stewart SS, Smith G, Appel SH. A Rating Scale for Amyotrophic Lateral Sclerosis: Description and Preliminary Experience. Ann Neurol 1987; 22: 328-333 